\title{
ADAM proteases involved in inflammation are differentially altered in patients with gastritis or ulcer
}

\author{
NURAY ERIN $^{1}$, SEMA TÜRKER $^{2}$, ÖZLEM ELPEK $^{3}$ and BÜLENT YILDIRIM ${ }^{2}$ \\ Departments of ${ }^{1}$ Medical Pharmacology, ${ }^{2}$ Internal Medicine and ${ }^{3}$ Pathology, \\ School of Medicine, Akdeniz University, Antalya 07070, Turkey
}

Received May 18, 2017; Accepted October 11, 2017

DOI: $10.3892 /$ etm.2017.5619

\begin{abstract}
ADAM metallopeptidase domain (ADAM)9, 10 and 17 have $\alpha$-secretase activity that regulates ectodomain shedding of factors involved in inflammation, cell proliferation, angiogenesis, and wound healing. The secretase activity of ADAM proteins is known to induce an inflammatory response. However, under certain conditions, a lack of secretase activity may induce inflammation suggesting differential roles of ADAM proteins with secretase activity. To the best of our knowledge, the present study evaluated the changes in $\alpha$-secretase activity and expression of associated ADAM proteases (ADAM9, 10 and 17) in the gastric mucosa of patients with gastritis and ulcers, for the first time. Gastroduedonal mucosal samples from 42 patients were snap-frozen to determine changes in $\alpha$-secretase activity. Twenty-four of these patients had gastritis, 9 patients had duedonal ulcers and 9 patients did not have any pathological changes. Paraffin-embedded gastric specimens $(n=32)$ were used for immunohistochemical detection of ADAM9, ADAM10 and ADAM17. $\alpha$-secretase activity of the gastric mucosa of healthy subjects was significantly higher compared with the uninvolved mucosa of patients with gastritis or ulcer. These results were associated with the immunohistochemical staining results, which demonstrated that ADAM10 expression markedly decreased in glandular epithelial cells and ADAM9 expression was lost in foveolar epithelial cells of gastric mucosa adjacent to ulcer. However, ADAM17 expression was increased in the normal gastric mucosa of patients with bleeding peptic ulcers and in the gastric mucosa adjacent to the ulcer suggesting a counteracting role of ADAM17. Decreased ADAM9 and 10 expression, and an associated decrease in $\alpha$-secretase activity may predispose to chronic gastritis and ulcer. Further studies are required to
\end{abstract}

Correspondence to: Professor Nuray Erin, Department of Medical Pharmacology, School of Medicine, Akdeniz University, B-blok kat 1 Immunoloji, Antalya 07070, Turkey

E-mail: nerin@akdeniz.edu.tr

Key words: $\alpha$-secretase activity, gastritis, ulcer, ADAM10, ADAM17, ADAM9 determine the possible etiological role of increased ADAM17 expression.

\section{Introduction}

Chronic gastritis and gastroduodenal ulcers are common and debilitating health problems worldwide. Most widely used therapies for these conditions involve reduction in gastric acid secretion which may have important side effects (1) such as increased risk of infectious complications and nutritional deficiencies (2). Hence better understanding of underlying pathology is required for more effective treatment strategies.

The ADAM family of proteins are a class of disintegrins and metalloproteinases (ADAMs), that contain pro-, metalloproteinase, disintegrin, cysteine-rich, epidermal growth factor (EGF)-like and cytoplasmic domains (3-5). These domains are involved in protease activity, adhesion, fusion, and signaling functions (4-8). Several members of ADAM proteins including ADAM9, 10 and 17 have $\alpha$-secretase activity regulating ectodomain shedding of factors involved in determining cellular fate, cell migration, wound healing, cell proliferation, angiogenesis, inflammation and control of neurodegenerative diseases (9-15) ADAM10 is structurally highly conserved in Drosophila, Xenopus, and C. Elegans, and is critical in vertebrate development. Similarly null mutants for ADAM17 die in utero or fail to survive beyond 1 week of age (16). Mice lacking ADAM9 however, are viable and exhibit no major pathologic changes indicative of redundancy by other ADAM proteases (16).

ADAM9 cleaves and releases factors that have key functions in wound healing such as EGF, fibroblast growth factor receptor 2-IIIb as well as heparin-binding EGF-like growth factor (17). Similarly migration of epithelial cells which is critical for wound healing is mediated by ADAM10 (18). Furthermore ADAM9, 10 and 17-induced release of EGFR ligands that are involved in wound healing in the skin $(19,20)$. EGF, one of the EGFR ligand, is also involved in mucosal repair (21-23).

Despite their role in tissue repair, secretase activity of ADAM proteins may aggravate inflammation (24) suggesting that ADAM proteins may have counteracting roles in gastroduedonal inflammatory diseases.

Infection by $H$. pylori has been estimated as $50-80 \%$ of the world's population depending on the developing state of the 
countries (25). H. pylori produces gastritis in most infected individuals (26). Studies using RT-PCR demonstrated that, in biopsies of the gastric antrum, levels of ADAM10 and ADAM17 are high in patients infected with H.pylori, compared to uninfected subjects with normal gastric mucosa (27). It is however not know how ADAM proteins are altered in patients with gastritis and $H$.pylori infection.

ADAM proteases are widely studied in wide-range of pathophysiological conditions including gastrointestinal carcinogenesis, and specific inhibitors or activators of these proteases are considered for treatment of various diseases (28). Given their functions in development, inflammation and wound healing, it is likely that they are also involved in gastrointestinal diseases. Their role in chronic gastritis and gastroduedonal ulcer however, is poorly examined and according to our knowledge there is no study conducted in samples of patients with gastritis or ulcer. Hence the goal of the study was to compare the changes in $\alpha$-secretase activity and protein expression of ADAM9, 10 and 17 in patients with gastritis or gastroduedonal ulcers in the presence and absence of $H$.pylori infection.

\section{Materials and methods}

Gastroduedonal mucosal samples were obtained from 42 patients who had upper gastrointestinal endoscopy for symptoms of dyspepsia for determination of changes in $\alpha$-secretase activity. The age of the patients ranged from 25 to 50 years. Eighteen of these patients were female and 15 were male. Twenty-four of these patients had gastritis, 9 of them had duedonal ulcers and 9 of them did not have any pathological changes. Eight of the patients with gastritis were positive for $H$. pylori infection. Exclusion criteria included the presence of malignancy, Diabetes Mellitus, rheumatologic diseases, or chronic lung diseases. The study protocol was approved by the Committee of Ethics at the Faculty of Medicine, Akdeniz University (Antalya, Turkey). Procedures were conducted according to the principles expressed in the Declaration of Helsinki. Patients gave consent for obtaining biopsies during the endoscopy. Patients were not under specific treatment for gastritis or ulcer. Endoscopic appearance of the lesions was used for the diagnosis of gastric and duodenal ulcers. Biopsies were obtained from the lesion, from neighboring normal looking gastric mucosa at the farthest possible distance from the lesion in case of gastritis and a 3-4 cm distance from the ulcer. Biopsies snap-frozen in liquid nitrogen were kept at $-80^{\circ} \mathrm{C}$. Approximately $1 \mathrm{ml}$ of gastric juice was collected from each patient during endoscopy. Presence of $H$. pylori infection was verified using a rapid urease assay [CLO test; Mcfarlane Medical Equipment (Holdings) Pty. Ltd., Surrey Hills, Australia] and HpFast test (GI Supply, Camp Hill, PA, USA) which was performed at the time of endoscopy.

Paraffin-embedded gastric specimens $(n=30)$ were used for immunohistochemical detection of ADAM9, ADAM10 and ADAM17. These specimens were from patients who were $25-68$ years old (mean \pm SD, $43.0 \pm 12.8$ years) with a male/female ratio of 2:1. Tissue specimens were divided into four groups: Group I (Control group), gastric mucosa from 6 previously healthy patients who had an urgent surgery for gastric perforation due to penetrating injuries; group II, normal appearing gastric mucosa from 6 patients who underwent partial gastrectomy for bleeding peptic ulcer; group III, gastric mucosa adjacent to ulcers from 7 patients operated for gastric ulcer; and group IV, gastric mucosa from 11 patients diagnosed with gastritis.

Measurement of $\alpha$-secretase like activity. $\alpha$-secretase activity in snap-frozen tissues was measured using a commercially available kit (cat. no. AS-72085; Anaspec, Fremont, CA, USA). The SensoLyte 520 TACE Activity Assay kit contains a QXL ${ }^{\mathrm{TM}} / 5$-FAM FRET substrate, derived from a sequence surrounding the cleavage site of TACE. In the intact FRET peptide, the fluorescence of 5-FAM is quenched by QXL $^{\text {TM }} 520$. In the presence of $\alpha$-secretase activity, FRET substrate is cleaved into two separate fragments resulting in an increase of 5-FAM fluorescence which can be monitored at excitation/emission $=490 \mathrm{~nm} / 520 \mathrm{~nm}$. For this assay approximately $50-80 \mathrm{mg}$ of tissues were lysed in lysis buffer by brief sonication and $10-25 \mathrm{ml}$ of sample was used for the assay. TAPI- 0 , an inhibitor of $\alpha$-secretase, was also included to determine the specificity of the activity observed. Data was expressed as pg product/mg tissue.

Immunohistochemistry. Immunostaining was performed on formalin fixed, paraffin wax embedded sections. Primary antibodies used in the study are given in Table I.

Sections from each block were deparaffinized and antigen retrieval was achieved by heating in a microwave oven for $10 \mathrm{~min}$. Specific staining was performed by incubation with primary antibodies for $60 \mathrm{~min}$ and with secondary biotinylating antibody for $15 \mathrm{~min}$ and streptavidin for $15 \mathrm{~min}$. Renal tissue was used as a positive control. Staining was evaluated separately in foveolar, glandular and endocrine cells. The staining pattern was classified as focal or diffuse. The intensity of staining was classified as: 1 , weak; 2 , moderate; and 3 , strong. The distribution of staining (cytoplasmic or membranous) was also noted.

Statistical analysis. The differences in the immunostainings among different groups were analyzed using ANOVA and Turkey-Kramer multiple comparison test. Results of $\alpha$-secretase activity were analyzed using t-test.

\section{Results}

Changes in $\alpha$-secretase activity of gastroduedonal mucosa. $\alpha$-secretase activity was determined in freshly frozen mucosal tissues. As seen in Fig. 1, $\alpha$-secretase activity of gastric mucosa of healthy subjects was significantly higher than uninvolved mucosa (lesion-free) of patients with gastritis or with ulcer. These results suggest that patients with low $\alpha$-secretase activity are at risk for developing gastritis and ulcer. On the other hand gastric mucosa at the site of ulcer had the higher levels of $\alpha$-secretase activity compared to uninvolved mucosa. Similarly, $\alpha$-secretase activity levels of inflamed mucosa of gastritis patients were not significantly different from the levels of gastric mucosa from healthy subjects. Immune infiltrates may contribute to enhanced secretase activity in these tissues.

The effects of $H$. pylori infection on $\alpha$-secretase activity were also determined. Although $\alpha$-secretase activity of 
Table I. Antibodies used for immunohistochemistry.

\begin{tabular}{llcl}
\hline Antibody & Clonality & Dilution & \multicolumn{1}{c}{ Source } \\
\hline ADAM 9 & Polyclonal & $1: 100$ & GenScript, USA \\
ADAM 10 & Polyclonal & $1: 100$ & Abcam, UK \\
ADAM 17 & Monoclonal & $1: 100$ & Abcam, UK
\end{tabular}

ADAM, ADAM metallopeptidase domain.

uninvolved (lesion-free) mucosa of patients with $H$. pylori infection was higher, it did not reach statistical significance probably because of limited number of samples in $H$. pylori infected group $(\mathrm{n}=8, \mathrm{n}=25$ for patients without $H$. pylori infection).

Changes in expression of ADAM 9, ADAM10 and ADAM17. Membranous and cytoplasm expression was observed in cells stained with ADAM9, ADAM10 and ADAM17. The distribution and intensity of staining with ADAM9, ADAM10 and ADAM17 in all groups are summarized in Table II.

Foveolar epithelial cells. ADAM9 was positive in $66 \%$ of cases in control group and in all samples obtained from normal appearing gastric mucosa of patients who underwent partial gastrectomy for bleeding peptic ulcer. However ADAM9 expression was not detected in gastric mucosa adjacent to ulcer and mucosa with gastritis. Hence the difference in ADAM9 expression between normal mucosa and inflamed mucosa was significant $(\mathrm{P}<0.05)$ (Fig. 2).

ADAM10 expression was noted only in one case with gastritis; the remaining cases were negative. Positive staining with ADAM17 was frequently observed in normal appearing gastric mucosa of patients with bleeding peptic ulcer $(100 \%)$ and gastric mucosa adjacent to ulcer (86\%) which was significantly higher than control mucosa (67\%) and mucosa involved with gastritis $(37 \%)(\mathrm{P}<0.05)$ (Fig. 3).

Glandular epithelial cells. ADAM9 expression was noted in all groups (Fig. 2). Similarly ADAM17 expression was observed in a great majority of cases, except one case in gastric mucosa adjacent to ulcer was negative (Fig. 4). On the other hand, ADAM10 expression was significantly higher in normal and normal appearing mucosa of patients with ulcer when compared to gastric mucosa adjacent to ulcer and mucosa involved with gastritis $(\mathrm{P}<0.05)$.

Endocrine cells. While endocrine cells did not express ADAM9, ADAM17, but consistently expressed ADAM10 in all cases (Fig. 3).

\section{Discussion}

We here reported for the first time that $\alpha$-secretase activity of gastric mucosa of healthy subjects is significantly higher than uninvolved mucosa (lesion-free) of patients with gastritis or ulcer. These results were somewhat in correlation with the immunohistochemical staining which demonstrated that

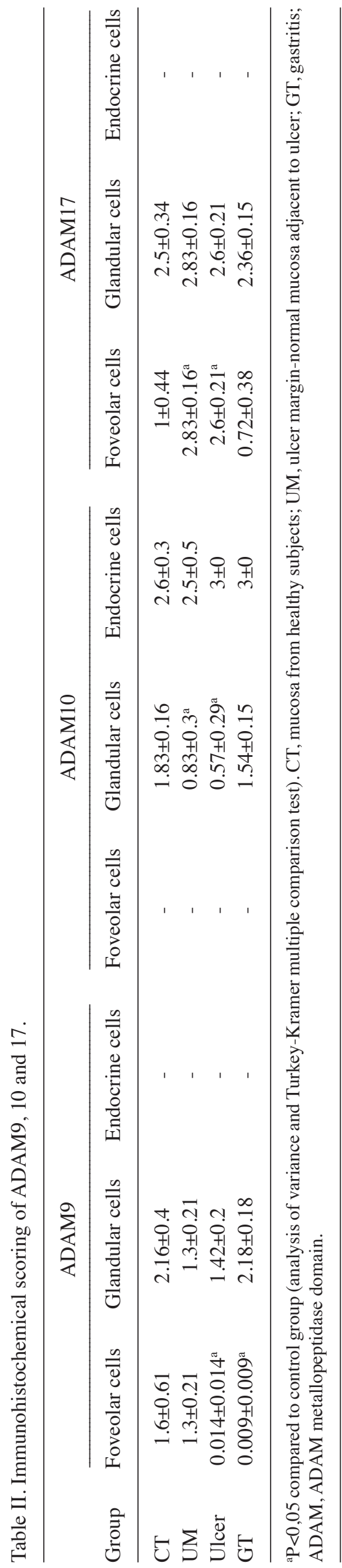



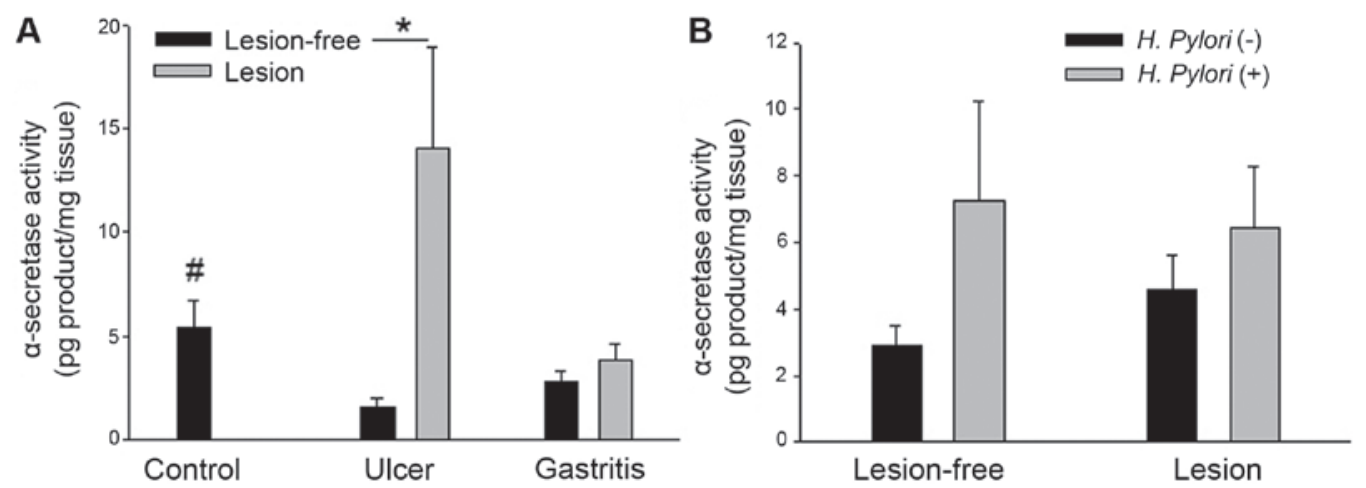

Figure 1. Changes in $\alpha$-secretase activity. Control denotes patients who did not have gastritis or ulcer. (A) $\alpha$-secretase activity of control group was significantly higher compared to lesion free areas of mucosa from patients with gastritis or ulcer $\left({ }^{*} \mathrm{P}<0.05\right)$. Mucosal samples obtained from lesion area of patients with ulcer have significantly higher levels of $\alpha$-secretase activity ( $\mathrm{P}<0.05$ ). (B) Comparison of $\alpha$-secretase activity of patients with $H$. pylori infection ( $\mathrm{n}=8$ ) and without infection $(\mathrm{n}=25)$.
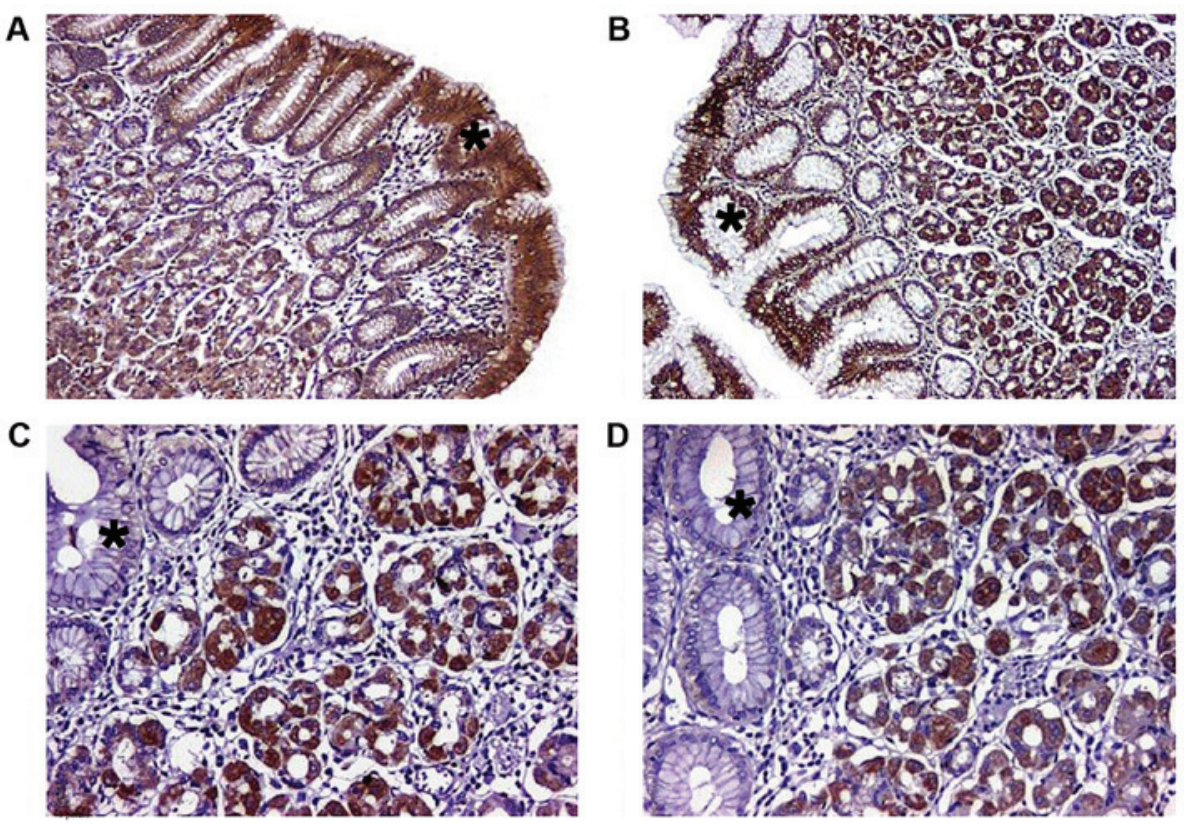

Figure 2. ADAM9 staining of gastric mucosa. ADAM9 expression by foveolar epithelium (asterisks) is observed only in normal mucosa (A) and in normal appearing mucosa from surgical margins (B). Foveolar epithelium in gastric mucosa close to ulcer (C) and in chronic gastritis (D) were negative. ADAM9, monoclonal antibody, counterstained with Mayers Haemotoxylin. (A and B) magnification, x100; (C and D) magnification, x200. ADAM9, ADAM metallopeptidase domain 9.

ADAM10, main $\alpha$-secretase, decreased markedly in glandular epithelial cells adjacent to ulcer and ADAM9 expression was lost in foveolar epithelial cells in gastric mucosa adjacent to ulcer.

Common feature of ADAM9, 10 and 17 is the $\alpha$-secretase activity which is important for ecdodomain shedding of growth factors and inflammatory mediators (11-15). There are nearly a hundered substrates of ADAM9, 10 and 17 have been identified, which are involved in important biological processes including immune response, embryogenesis, neuroprotection and wound healing (20). Specifically ADAM9, 10 and 17-induced release of EGFR ligands are involved in wound healing in the skin $(19,20)$. EGF, one of the EGFR ligand, is involved in mucosal repair (21-23) demonstrating that decreased $\alpha$-secretase activity may prolong healing of gastric ulcers.
Secretase activity of ADAM proteins is known to induce inflammatory response (24); under certain conditions, however, lack of secretase activity may induce inflammation. Specifically it was recently shown that LY900009, a selective secretase inhibitor induced grade III mucosal inflammation in a phase I study (29). These results suggest that patients with low $\alpha$-secretase activity may predispose to gastritis and ulcer.

Gastric mucosa at the site of ulcer had a higher level of $\alpha$-secretase activity compared to uninvolved mucosa. Similarly $\alpha$-secretase activity level of inflamed mucosa of gastritis patients was not significantly different from the levels of gastric mucosa from healthy subjects. ADAM9 and 10 expressions were lost in inflamed mucosa and in ulcers. ADAM17 expression however was higher in gastric mucosa adjacent to ulcer compared to healthy mucosa. ADAM17 expression, on the other hand did not increase in the samples of gastritis. Hence higher levels of 
A

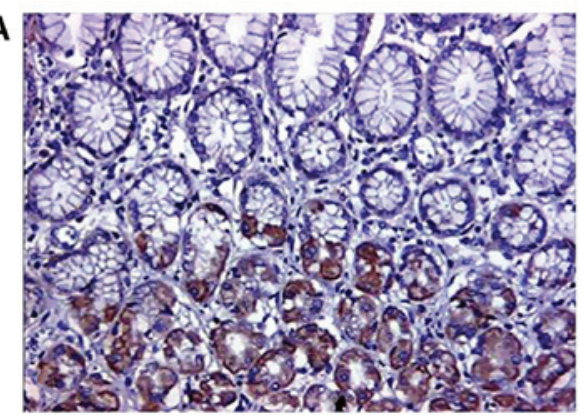

C

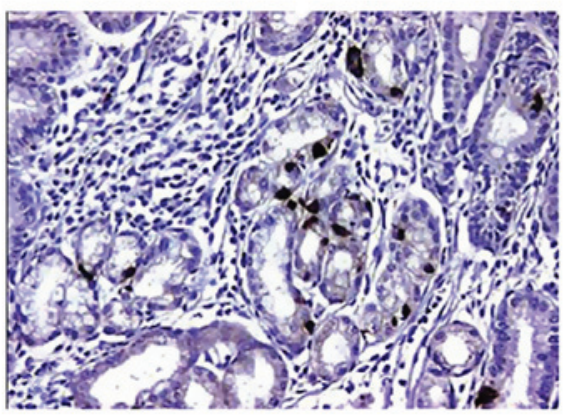

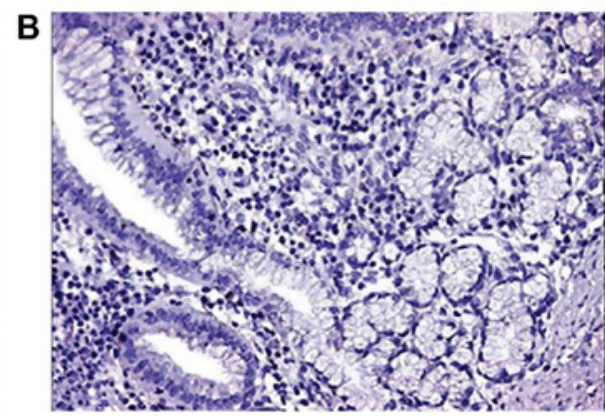

\section{D}

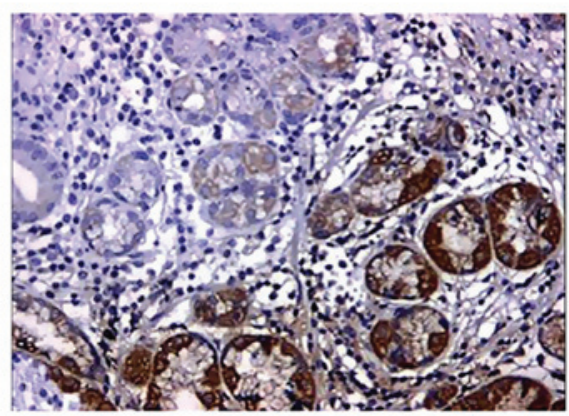

Figure 3. ADAM10 is expressed in the cytoplasm of the gastric glands in normal mucosa (A) and in gastritis (D). Normal appearing mucosa from surgical margins (B) is completely negative. While, a few endocrine cells between gastric glands show strong ADAM10 expression in gastric mucosa close to ulcer (C), other cells remain negative. ADAM10 monoclonal antibody, counterstained with Mayers Haemotoxylin. Magnification, x200. ADAM10, ADAM metallopeptidase domain 10 .
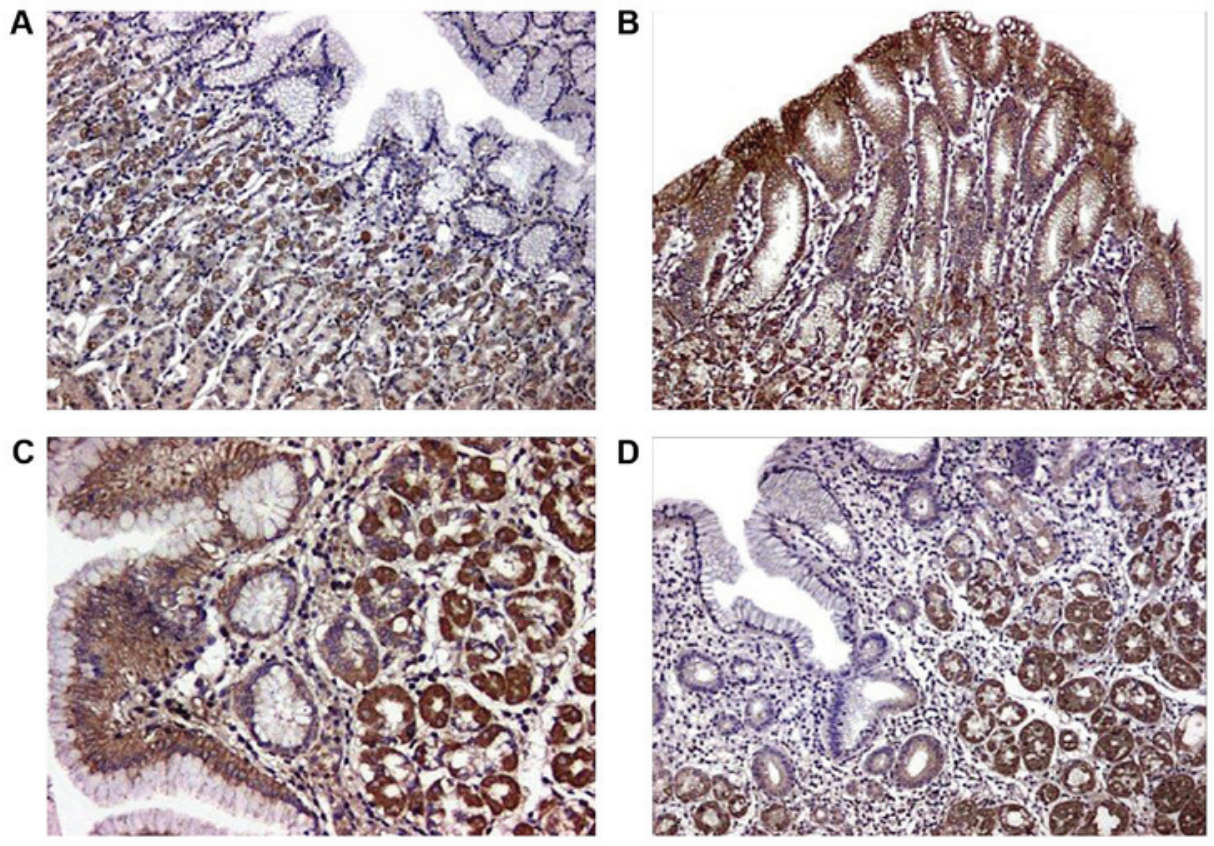

Figure 4. ADAM17 is not expressed in normal mucosa (A) and in gastritis (D). Gastric glands in normal appearing mucosa from surgical margins (B) and in gastric mucosa close to ulcer (C) show cytoplasmic ADAM17 expression (ADAM17 monoclonal antibody, counterstained with Mayers Haemotoxylin. (A and B) magnification, x100; (C and D) magnification, x200. ADAM17, ADAM metallopeptidase domain 17.

$\alpha$-secretase activity observed in these samples are at least partly due to infiltrating immune cells (30).

We not only observed differential expression of ADAMs in gastric mucosal cells here, but also observed differential regulation of ADAM proteins during pathological conditions. Specifically ADAM17 was increased in normal appearing gastric mucosa of patients with bleeding peptic ulcer and gastric mucosa adjacent to ulcer suggesting a counteracting role for ADAM17 in gastric ulcer pathogenesis. Previous studies also support these findings such that among the ADAMs with $\alpha$-secretase activity, ADAM17 was shown to have distinct functions. For example ADAM17, which is also known as tumor necrosis factor $\alpha$ (TNF- $\alpha$ ) converting enzyme (TACE), cleaves membrane-bound pro-TNF- $\alpha$ to soluble TNF- $\alpha$ which may enhance inflammatory response (31). Although ADAM10 also cleaves pro-TNF- $\alpha$ in cell-free assays $(32,33)$, 
overexpression of ADAM10 in ADAM17-deficient cells does not promote TNF- $\alpha$ cleavage (34) demonstrating that ADAM17 is the main shedase for TNF- $\alpha$. In accordance, aspirin-induced gastric mucosal damage as well as increased TNF- $\alpha$ release was prevented by inhibitors of ADAM17 (35). ADAM17, but not ADAM10 is responsible from generation of soluble interleukin-15R $\alpha$ (36), which is a proinflammatory molecule associated with progression of head and neck carcinoma (36). Increase ADAM17 activity was shown in inflamed colonic mucosa and ulcerative colitis (37). Specific ADAM17 inhibitor GM6001 was shown to inhibit indomethacin-induced intestinal damage and ulceration (38). Among ADAMs, the strongest evidence for a role in malignancy exists for ADAM17, which is overexpressed and associated with tumorogenesis in the breast, ovary, kidney, colon, pancreas and gastric adenocarcinoma (27,39-42). Hence differential activities among ADAMs with $\alpha$-secretase activity indicate differential roles for ADAM9, 10 and 17 in pathogenesis of gastroduedonal diseases. Given the information above, increased ADAM17 expression in gastroduedonal ulcers may involve in pathogenesis of ulcers. Further studies using specific ADAM17 inhibitors are required to determine exact role of ADAM17 in gastroduedonal ulcers.

There are few studies examining the expression of ADAM proteins in gastric mucosa. Presence of ADAM10 and 17 at transcriptional level was reported in human gastric mucosa (27). In another study, ADAM17 immunostaining was observed in gastric glands but not in foveolar epithelium (43) which is partly consistent with our data such that ADAM17 was also observed in majority of glandular cells of healthy subjects. We, however also observed ADAM17 expression in $67 \%$ of foveolar cells. This discrepancy may be due to the differences in sensitivity and concentration of the antibodies used.

We also observed here that glandular epithelial cells expressed all three ADAMs but endocrine cells only expressed ADAM10. Previously membranous expression of ADAM10 in endocrine and exocrine cells of pancreas was reported (16). Hence ADAM10 may have a distinct role in regulation of endocrine cells. Further studies are required to explore these possibilities.

Lastly we also examine possible effects of $H$.pylori infection on $\alpha$-secretase activity since $H$. pylori infection may increase ADAM proteases (27). We observed a borderline increase in $\alpha$-secretase activity of uninvolved (lesion-free) mucosa of patients with $H$. pylori infection, but the number of patients in this group was limited and further studies are required.

In conclusion, our results demonstrated that decreased ADAM9 and 10 expression and related decrease in $\alpha$-secretase activity may predispose chronic gastritis and ulcer. Actual cause of decreased $\alpha$-secretase activity and related ADAMs require further studies.

\section{Acknowledgements}

The present study was supported by funds from Akdeniz University Research Unit, Antalya, Turkey (grant no. 2008.04.0103.003). Experiments were performed in part in Health Sciences Research Center of Akdeniz University
(SBAUM; Antalya, Turkey). Authors thank Senior Technician Özlem Duymus for her technical help.

\section{References}

1. El-Omar EM, Oien K, Murray LS, El-Nujumi A, Wirz A, Gillen D, Williams C, Fullarton G and McColl KE: Increased prevalence of precancerous changes in relatives of gastric cancer patients: Critical role of H. pylori. Gastroenterology 118: 22-30, 2000.

2. Ali T, Roberts DN and Tierney WM: Long-term safety concerns with proton pump inhibitors. Am J Med 122: 896-903, 2009.

3. Wolfsberg TG, Primakoff P, Myles DG and White JM: ADAM, a novel family of membrane proteins containing A Disintegrin And Metalloprotease domain: Multipotential functions in cell-cell and cell-matrix interactions. J Cell Biol 131: 275-278, 1995.

4. Schlondorff J and Blobel CP: Metalloprotease-disintegrins: Modular proteins capable of promoting cell-cell interactions and triggering signals by protein-ectodomain shedding. J Cell Sci 112: 3603-3617, 1999.

5. Black RA and White JM: ADAMs: Focus on the protease domain. Curr Opin Cell Biol 10: 654-659, 1998.

6. Almeida EA, Huovila AP, Sutherland AE, Stephens LE, Calarco PG, Shaw LM, Mercurio AM, Sonnenberg A, Primakoff P, Myles DG and White JM: Mouse egg integrin alpha 6 beta 1 functions as a sperm receptor. Cell 81: 1095-1104, 1995.

7. Yuan R, Primakoff P and Myles DG: A role for the disintegrin domain of cyritestin, a sperm surface protein belonging to the ADAM family, in mouse sperm-egg plasma membrane adhesion and fusion. J Cell Biol 137: 105-112, 1997.

8. Howard L, Lu X, Mitchell S, Griffiths S and Glynn P: Molecular cloning of MADM: A catalytically active mammalian disintegrin-metalloprotease expressed in various cell types. Biochem J 317: 45-50, 1996.

9. Edwards DR, Handsley MM and Pennington CJ: The ADAM metalloproteinases. Mol Aspects Med 29: 258-289, 2008.

10. Rocks N, Paulissen G, El Hour M, Quesada F, Crahay C, Gueders M, Foidart JM, Noel A and Cataldo D: Emerging roles of ADAM and ADAMTS metalloproteinases in cancer. Biochimie 90: 369-379, 2008.

11. Koike H, Tomioka S, Sorimachi H, Saido TC, Maruyama K, Okuyama A, Fujisawa-Sehara A, Ohno S, Suzuki K and Ishiura S: Membrane-anchored metalloprotease MDC9 has an alpha-secretase activity responsible for processing the amyloid precursor protein. Biochem J 343 Pt 2: 371-375, 1999.

12. Hartmann D, de Strooper B, Serneels L, Craessaerts K, Herreman A, Annaert W, Umans L, Lübke T, Lena Illert A, von Figura K and Saftig P: The disintegrin/metalloprotease ADAM 10 is essential for Notch signalling but not for alpha-secretase activity in fibroblasts. Hum Mol Genet 11: 2615-2624, 2002.

13. Lammich S, Kojro E, Postina R, Gilbert S, Pfeiffer R, Jasionowski M, Haass C and Fahrenholz F: Constitutive and regulated alpha-secretase cleavage of Alzheimer's amyloid precursor protein by a disintegrin metalloprotease. Proc Natl Acad Sci USA 96: 3922-3927, 1999.

14. Buxbaum JD, Liu KN, Luo Y, Slack JL, Stocking KL, Peschon JJ, Johnson RS, Castner BJ, Cerretti DP and Black RA: Evidence that tumor necrosis factor alpha converting enzyme is involved in regulated alpha-secretase cleavage of the Alzheimer amyloid protein precursor. J Biol Chem 273: 27765-27767, 1998.

15. Deuss M, Reiss K and Hartmann D: Part-time alpha-secretases: The functional biology of ADAM 9, 10 and 17. Curr Alzheimer Res 5: 187-201, 2008.

16. Asayesh A, Alanentalo T, Khoo NK and Ahlgren U: Developmental expression of metalloproteases ADAM 9, 10 and 17 becomes restricted to divergent pancreatic compartments. Dev Dyn 232: 1105-1114, 2005.

17. Peduto L, Reuter VE, Shaffer DR, Scher HI and Blobel CP: Critical function for ADAM9 in mouse prostate cancer. Cancer Res 65: 9312-9319, 2005.

18. Maretzky T, Reiss K, Ludwig A, Buchholz J, Scholz F, Proksch E, de Strooper B, Hartmann D and Saftig P: ADAM10 mediates E-cadherin shedding and regulates epithelial cell-cell adhesion, migration and beta-catenin translocation. Proc Natl Acad Sci USA 102: 9182-9187, 2005.

19. Higashiyama S and Nanba D: ADAM-mediated ectodomain shedding of HB-EGF in receptor cross-talk. Biochim Biophys Acta 1751: 110-117, 2005. 
20. Horiuchi K, Le Gall S, Schulte M, Yamaguchi T, Reiss K, Murphy G, Toyama Y, Hartmann D, Saftig P and Blobel CP: Substrate selectivity of epidermal growth factor-receptor ligand sheddases and their regulation by phorbol esters and calcium influx. Mol Biol Cell 18: 176-188, 2007.

21. Lemoine NR, Leung HY and Gullick WJ: Growth factors in the gastrointestinal tract. Gut 33: 1297-1300, 1992.

22. Playford RJ: Peptides and gastrointestinal mucosal integrity. Gut 37: 595-597, 1995.

23. Playford RJ and Wright NA: Why is epidermal growth factor present in the gut lumen? Gut 38: 303-305, 1996.

24. Scheller J, Chalaris A, Garbers C and Rose-John S: ADAM17: A molecular switch to control inflammation and tissue regeneration. Trends Immunol 32: 380-387, 2011.

25. Bartnik W: Clinical aspects of Helicobacter pylori infection. Pol Arch Med Wewn 118: 426-430, 2008

26. Oh JD, Kling-Backhed H, Giannakis M, Xu J, Fulton RS, Fulton LA, Cordum HS, Wang C, Elliott G, Edwards J, et al: The complete genome sequence of a chronic atrophic gastritis Helicobacter pylori strain: evolution during disease progression. Proc Natl Acad Sci USA 103: 9999-10004, 2006.

27. Yoshimura T, Tomita T, Dixon MF, Axon AT, Robinson PA and Crabtree JE: ADAMs (a disintegrin and metalloproteinase) messenger RNA expression in Helicobacter pylori-infected, normal, and neoplastic gastric mucosa. J Infect Dis 185: 332-340, 2002.

28. Giebeler N and Zigrino P: A Disintegrin and metalloprotease (ADAM): Historical overview of their functions. Toxins (Basel) 8: 122, 2016

29. Pant S, Jones SF, Kurkjian CD, Infante JR, Moore KN, Burris HA, McMeekin DS, Benhadji KA, Patel BK, Frenzel MJ, et al: A first-in-human phase I study of the oral Notch inhibitor LY900009, in patients with advanced cancer. Eur J Cancer 56: $1-9,2016$.

30. Ebsen H, Lettau M, Kabelitz D and Janssen O: Subcellular localization and activation of ADAM proteases in the context of FasL shedding in T lymphocytes. Mol Immunol 65: 416-428, 2015.

31. Moss ML, Jin SL, Milla ME, Bickett DM, Burkhart W, Carter HL, Chen WJ, Clay WC, Didsbury JR, Hassler D, et al: Cloning of a disintegrin metalloproteinase that processes precursor tumour-necrosis factor-alpha. Nature 385: 733-736, 1997.

32. Lunn CA, Fan X, Dalie B, Miller K, Zavodny PJ, Narula SK and Lundell D: Purification of ADAM 10 from bovine spleen as a TNFalpha convertase. FEBS Lett 400: 333-335, 1997.

33. Rosendahl MS, Ko SC, Long DL, Brewer MT, Rosenzweig B, Hedl E, Anderson L, Pyle SM, Moreland J, Meyers MA, et al: Identification and characterization of a pro-tumor necrosis factor-alpha-processing enzyme from the ADAM family of zinc metalloproteases. J Biol Chem 272: 24588-24593, 1997.
34. Reddy P, Slack JL, Davis R, Cerretti DP, Kozlosky CJ, Blanton RA, Shows D, Peschon JJ and Black RA: Functional analysis of the domain structure of tumor necrosis factor-alpha converting enzyme. J Biol Chem 275: 14608-14614, 2000.

35. Fiorucci S, Antonelli E, Migliorati G, Santucci L, Morelli O, Federici B and Morelli A: TNFalpha processing enzyme inhibitors prevent aspirin-induced TNFalpha release and protect against gastric mucosal injury in rats. Aliment Pharmacol Ther 12: 1139-1153, 1998

36. Badoual C, Bouchaud G, Agueznay NH, Mortier E, Hans S, Gey A, Fernani F, Peyrard S, Puig PL, Bruneval P, et al: The soluble alpha chain of interleukin-15 receptor: A proinflammatory molecule associated with tumor progression in head and neck cancer. Cancer Res 68: 3907-3914, 2008.

37. Brynskov J, Foegh P, Pedersen G, Ellervik C, Kirkegaard T, Bingham A and Saermark T: Tumour necrosis factor alpha converting enzyme (TACE) activity in the colonic mucosa of patients with inflammatory bowel disease. Gut 51: 37-43, 2002.

38. Matsumoto H, Koga H, Iida M, Tarumi K, Fujita $M$ and Haruma K: Blockade of tumor necrosis factor-alpha-converting enzyme improves experimental small intestinal damage by decreasing matrix metalloproteinase-3 production in rats. Scand J Gastroenterol 41: 1320-1329, 2006.

39. Zhang TC, Zhu WG, Huang MD, Fan RH and Chen XF: Prognostic value of ADAM17 in human gastric cancer. Med Oncol 29: 2684-2690, 2012

40. Kenny PA and Bissell MJ: Targeting TACE-dependent EGFR ligand shedding in breast cancer. J Clin Invest 117: 337-345, 2007.

41. Bozkulak EC and Weinmaster G: Selective use of ADAM10 and ADAM17 in activation of Notch1 signaling. Mol Cell Biol 29: 5679-5695, 2009.

42. Szalad A, Katakowski M, Zheng X, Jiang F and Chopp M: Transcription factor Sp1 induces ADAM17 and contributes to tumor cell invasiveness under hypoxia. J Exp Clin Cancer Res 28: 129, 2009.

43. Schmuck R, Warneke V, Behrens HM, Simon E, Weichert W and Rocken C: Genotypic and phenotypic characterization of side population of gastric cancer cell lines. Am J Pathol 178: 1792-1804, 2011

This work is licensed under a Creative Commons Attribution-NonCommercial-NoDerivatives 4.0 International (CC BY-NC-ND 4.0) License. 